\title{
التوافق الزواجي وعلاقته بتقبل الذات لدى معلمات محافظة شمال الشرقية
}

\author{
خليفة بن أحمد القصابي \\ أستاذ مساعد في علم النفس التربوي \\ جامعة نزوى- سلطنة عُمان \\ kah73@unizwa.edu.om
}

حفصة بنت حمود بن ناصر المحرزية

ماجستير في الإرشاد النفسي بهدي

جامعة نزوى- سلطنة عُمان 
التو افق الزواجي وعلاقته بتقبل الذات لدى معلمات محافظة شمال الشرقية

\author{
حفصة بنت حمود بن ناصر المحرزية
}

ماجستير في الإرشاد النفسي- جامعة نزوى- سلطنة عُمان بـان

\author{
خليفة بن أحمد القصابي
}

أستاذ مساعد في علم النفس التربوي- جامعة نزوى- سلطنة عُمان

kah73@unizwa.edu.om

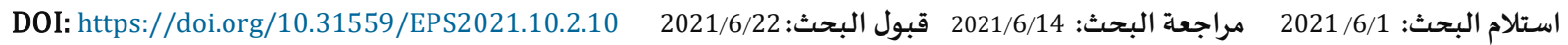

هدفت الدراسة إلى فحص العلاقة بين التوافق الزواجي وتقبل الذات لدى معلمات محافظة شمال الشرقية. حيث تكونت عينة الدراسة من (618) معلمة متزوجاة. ولتحقيق أهداف الدراسة تم استخدام الأدوات التالية: الأولى مقياس التوافق الزواجي ل( قاسم، 2015)، والأداة الثانية

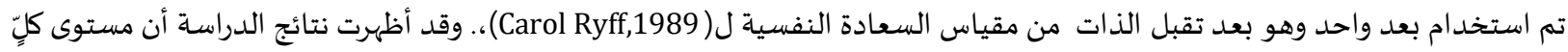
من التوافق الزواجي وتقبل الذات كانا مرتفعين، كما أظهرت النتائج أيضا عدم تأثير عدد سنوات الزواج على التوافق الزواجي إذ لا توجد فروق

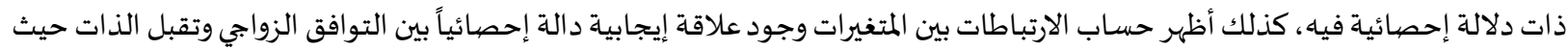
بينت تقبل الذات ما نسبته 21.8\% من التوافق الزواجي، وبينت أنه يمكن التنبؤ بالتوافق الزواجي من خلال تقبل، ومما أوصت باه الدراسة الاستفادة من العلاقة الارتباطية والتنبؤية بين تقبل الذات والتوافق الزواجي لحل الخلافات الزوجية وبناء البرامج الإرشادية في مجال الإرشاد

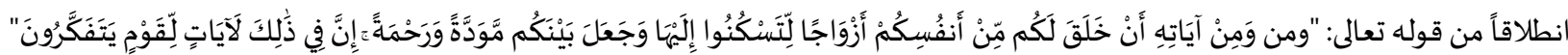

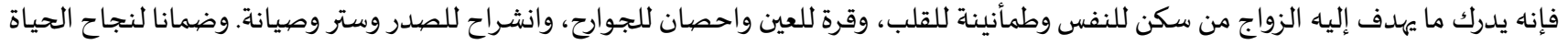

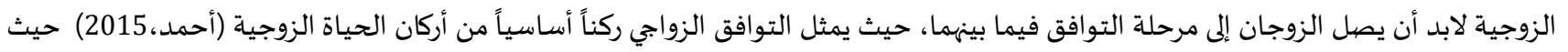

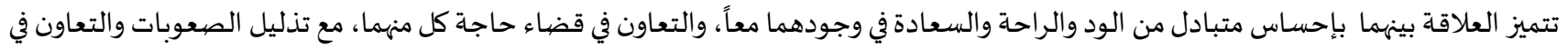

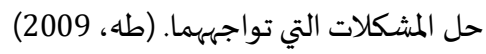

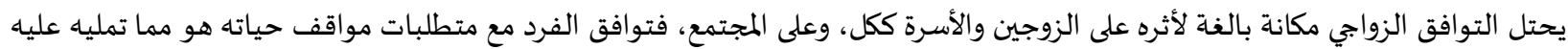

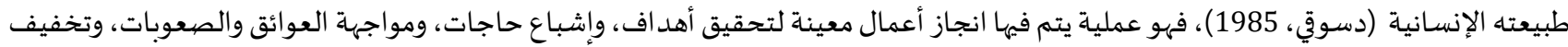

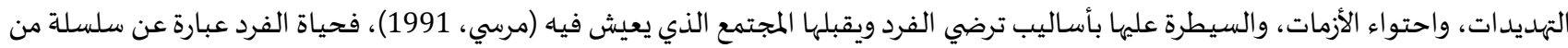

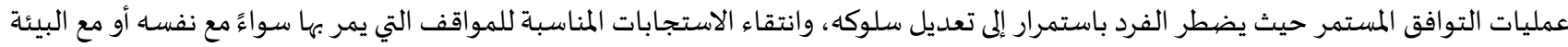

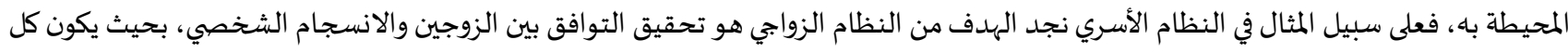


طرف منهما منفعلاً بالآخر ومنجذباً إليه، ومن هنا فإن التوافق الزواجي يعني: الميل النفسي المعبر عن المحبة والود والاتفاق والعلاقة الطيبة الحسنة

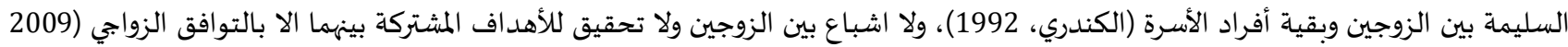

(APA,

ويرى بالي ودهينجرا وبارو (Bali, Dhingra \& Baru, 2010) أن تحقيق أكبر قدر من الرضا والسعادة مرتبط بالتوافق الزواجي بينهما، كما يرى

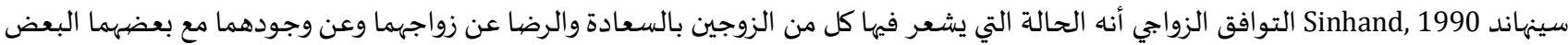

(Nema, 2013)

إن من أهم مقومات التوافق الزواجي كما ذكرتها الدراسات التوافق الديني البريكي (2016)، والنضج الانفعالي (بلميهوب، 2009)، والتوافق الاقتصادي (هلون، 2017)، والتوافق الجنسي (مناني، 2013)، والثقة المتبادلة (محمد، 2017).

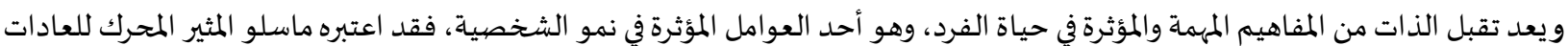
والسلوكيات التي تشكل تحقيق الفرد لذاته (النمر، 2016)، حيث يؤثر ذلك التقبل على معرفة الفرد لقدراته وإمكانياته وإيجابياته وسلبياته مع تقبله

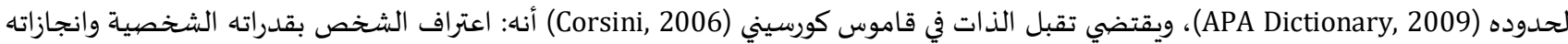
وتقبلها من غير قيود ولا شروط. في حين رأى جونزلز (Gonzalez, 2002) أن الصعوبة التي يجدها المرء في تقبله للآخرين إنما هي مرتبطة ارتباطاً وثيقاً بانخفاض تقبله لنفسـه. ويعد التوافق الزواجي عاملا من عوامل التوافق النفسي، وهو مرتبط ارتباطاً وثيقاً بعوامل الشخصية وسماتها، ولكن سمات الشخصية التي تساعد على تحقيق التوافق الزواجي تختلف باختلاف الزوجين، فالسمات الشخصية التي تتحلى بها الزوجات تختلف عن السمات التي يتحلى بها الأزواج (سليمان، (2005

كما أن المشكلات النفسية التي يتعرض لها الزوجان في مراحل حياتهما تتطلب نوعا من التوافق النفسي، ليستعينا باء على مواجهة الظروف الصعبة

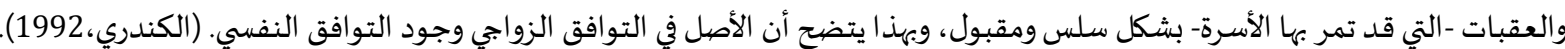
إذن حتى يستطيح الزوجان التوافق فيما بينهما لابد أن يتوافق كل منهما مع نفسه أولاً، ومن مظاهر التوافق النفسي هو تقبل الذات، حيث يعتبر من المفاهيم المهمة والمؤثرة في حياة الفرد، ويتكون هذا المفهوم من خلال تقبل الفرد لصفئاته وسلوكياته التي يحبها والتي لا يحبها أيضاً. (الشاذلي، 2004)

1.1. الدراسات السابقة:

تناولت عدد من الدراسات السابقة متغيري تقبل الذات والتوافق الزواجي من حيث الارتباط بينهما ومن حيث تأثير متغيرات أخرى على كل منهما أو

ففي فلسطين أجرت السلامين (2019) دراسة هدفت إلى هدفت إلى التعرف على العلاقة بين التوافق الزواجي والصحة النفسية لدى النساء

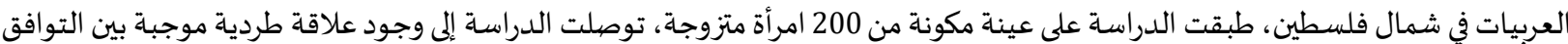
الزواجي والصحة النفسية، فيما تبين أن هناك فروقا تعزى إلى متغير عدد سنوات الزواج.

وفي الجز ائر أجرت زكيري (2018) دراسة هدفت إلى الكشف عن العلاقة بين التوافق الزواجي والتوافق النفسي لدى الأستاذة الجامعية المتزوجة. طبقت الدراسة على عينة شملت 30 أستاذة جامعية متزوجة، وقد أكدت أن هناك علاقة ارتباطية بين التوافق النفسي والتوافق الزواجي بلغت بمعامل ارتباط قدره 0.88.

Khorasani., Hosseini, Matbouei., Khafri, Vasli, \& وفي إيران هدفت دراسة كل من خرساني وحسيني وماتابوي وخافري وفردانجني ( Vardanjani 2017) إلى إمكانية التنبؤ بالتوافق الزواجي من تقبل الذات، كما يمكن التأثير على التوافق الزواجي عن طريق التأثير على مستوى تقبل الذات التهات وفي سويسرا أجرى إيرول و أرث (Erol \& Orth,20017) دراسة هدفت الكشف عن تأثير تقدير الناس لذاتهم على جودة علاقاتهم الرومانسية، وتفسر الارتباط بين احترام الذات وجودة العلاقة وقد أشارت نتائجها إلى أن تقدير الذات العالي مفيد في العلاقات الرومانسية. وفي مصر أجرت النمر (2016) دراسـة هدفت إلى معرفة طبيعة العلاقة بين تقبل الذات وأساليب التعلق وتقبل الآخر. وقد طبقت الدراسة على 394 طالباً وطالبة في جامعة القاهرة، حيث توصلت إلى وجود ارتباط إيجابي دال احصائيا بين تقبل الذات وتقبل الآخر. وفي السعودية أجرت صحاف (1436) هدفت إلى معرفة العلاقة بين التوافق الزواجي والاستقرار الأسري لدى المتزوجين بمدينة مكة المكرمة، طبقتها على عينة قدرها (459) زوج وزوجاة، توصلت إلى وجود علاقة ارتباطية دالة بين التوافق الزواجي والاستقرار الأسري. 
وفي إيران أجرى تايزادة وكالهوري (Taghizadeh \& Kalhori, 2015) هدفت إلى معرفة العلاقة بين تقبل الذات والرضا الزواجي لدى النساء، تم تطبيق الدراسة على 94 من الموظفات المتزوجات في جامعة بايام نور، وقد أظهرت النتائج أن هناك علاقة ذات ذات دلالة إحصائية بين الرضا الزوجي، وتقبل الذات.

وفي إيران أجرى كل من يدمجلايو وناصري وشاشتري وخالديان وأحرامي ( Yadalijamaloye, Naseri, Shoshtari, Khaledian, \& Ahrami

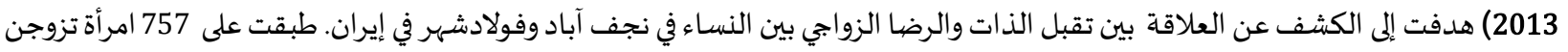

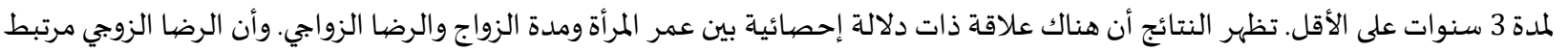
بشكل إيجابي بتقبل الذات في كلتا المدينتين. وهدفت دراسة الخالدي (2012) إلى الكشف عن درجة التوافق الزواجي لدى النساء الأردنيات العاملات وغير العاملات وعلاقتها بالمستوى التعليمي والعمر، تم تطبيق الدراسـةعلى عينة تكونت من ( 174) امرأة ، وتوصل أن هناك فروق ذات ذات دلالة إحصائية في التوافق الزواجي تعزى للعمر. في مصرقام زهران (2011) بإجراء دراسـة هدفت إلى التعرف على أثر برنامج إرشادي لتحسين التوافق الزواجي ومدى انعكاسـاء على مدى تقدير

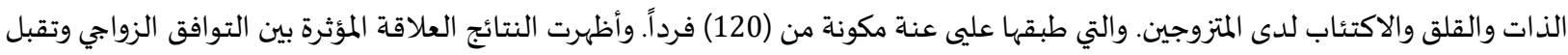

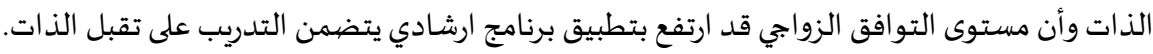

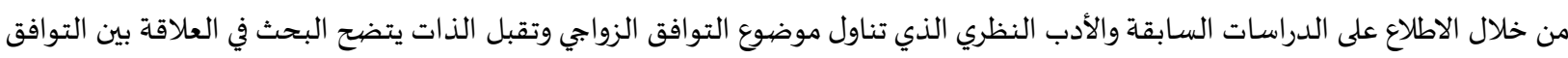

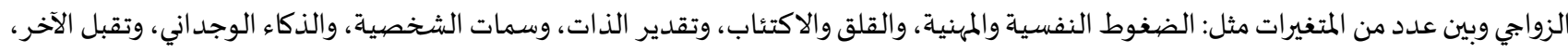

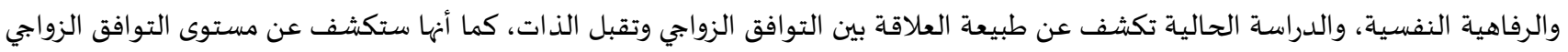

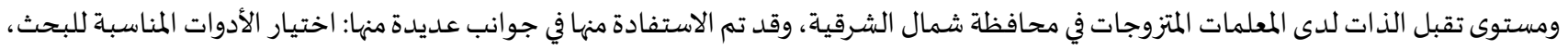
وتأكيد بعض جوانب الاطار النظري، وفي تفسير النتائج.

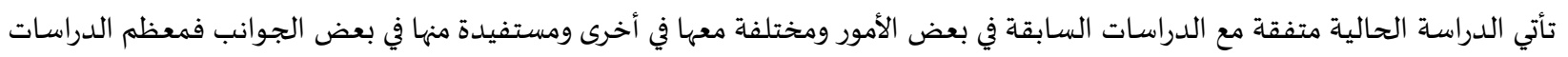

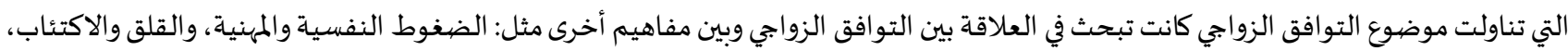

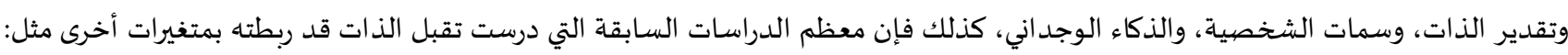

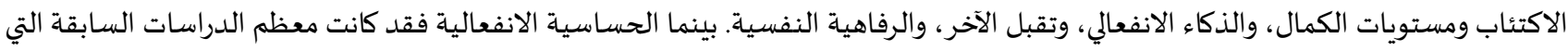

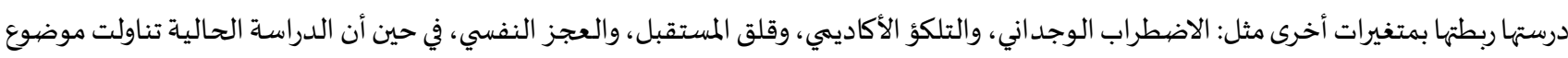

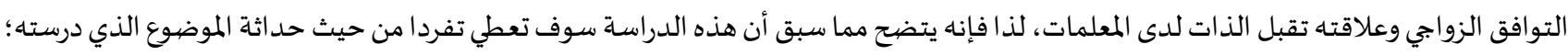

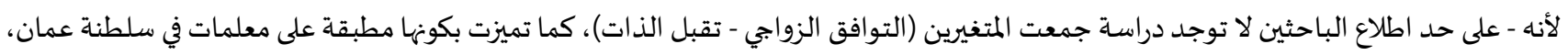
ومن حيث الاقتصار على الزوجات فقط فقد اتفقت هذه الدراسة مع بعض الدراسات السابقة من حيث تطبيقها على الزوجات فقط ، مثل مثل دراسة هديبل

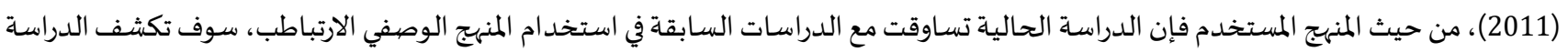
الحالية عن طبيعة العلاقة بين التوافق الزواجي وتقبل الذات، كما أنها ستكشف عن مستوى التوافق الزواجي ومستوى تقبل الذات الذات لدى المعلمات المتزوجات في محافظة عمانية هي شمال الشرقية مما ستسـاهم بذلك في دراسة المواضيع الخاصة بالحية بالحياة الزوجية والإرشاد الزواجي بشكل عام.

2.1.

لاحظ الباحثان من خلال التواصل والحديث مع عدد من المعلمات المتزوجات المحيطات بهما -سواءً على مستوى الأسرة أم على مستوى المجتمع -

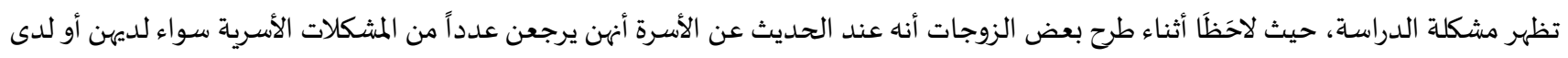

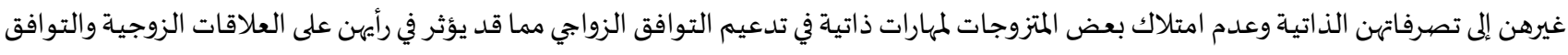

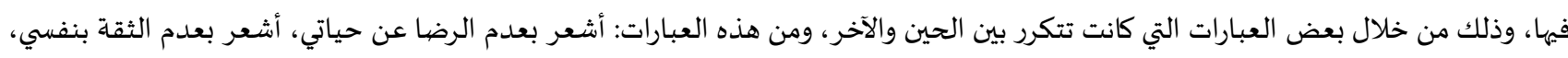

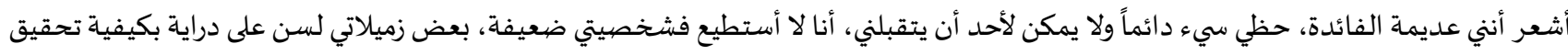

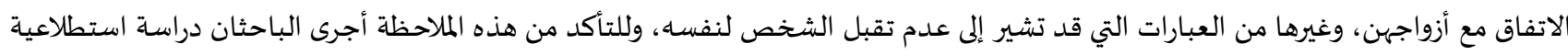

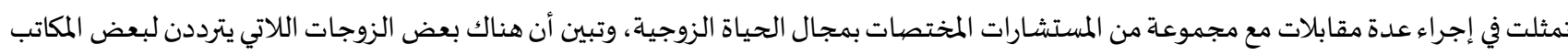

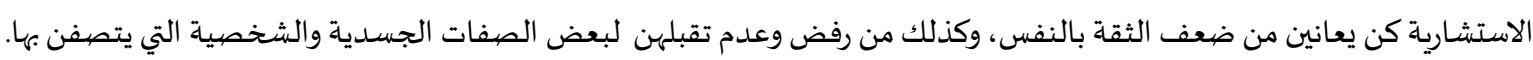
لذلك تولد لدى الباحثين تساؤل مفاده: ما العلاقة بين التو افق الزواجي بين التو افق الزواجي وتقبل الذات لئن لدى المعلمات المتزوجات في محافظة

شمال الشـرقية؟ 


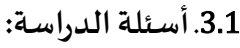

وينبثق من السؤال الرئيس الأسئلة الفرعية الآتية:

1. ما مستوى التوافق الزواجي، وتقبل الذات، لدى المعلمات المتزوجات في محافظة شمال الشرقية؟

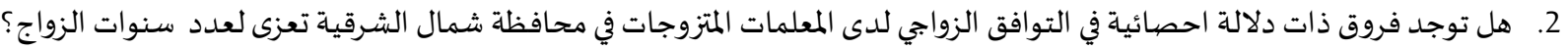

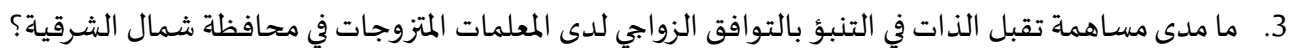

4.1 - 2.1 أهداف الدراسـة:

تهدف الدراسة الحالية إلى التعرف على مستوى التوافق الزواجي، وتقبل الذات، والتعرف على العلاقة الارتباطية بين التوافق الزواجي وتقبل الذات

لدى المعلمات المتزوجات في محافظة شمال الشرقية والتأكد من أثر سنوات الزواج على التوافق الزواجي لدى المعلمات المتزوجات في محافظة شمال

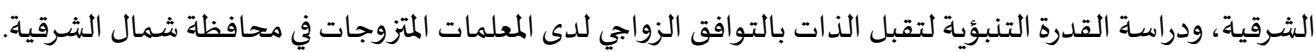

5.1 - أهمية الدراسة:

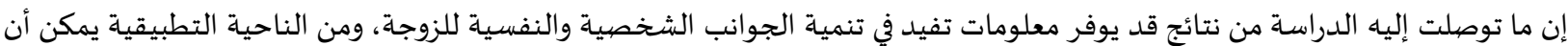
تساعد في بناء برامج وتقنيات إرشادية قائمة على التأثير على تقبل الذات لرفع مستوى التوافق الزواجي لدى المتزوجات، كما يمكن أن تسـاعد القائمين

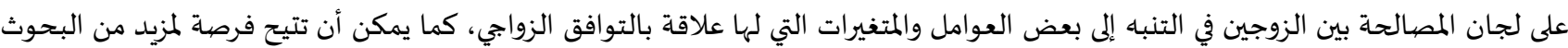
والدراسات المتعلقة بمثل هذا الموضيوع في المستقبل.

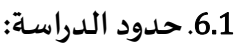

يتحدد مجال الدراسة بالمحددات التالية: زماناً بالعام الدراسي 2021/2020، ومكاناً بمحافظة شمال الشرقية بسلطنة عمان، وبشرياً بالمعلمات

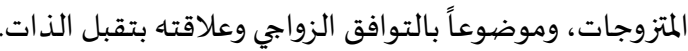

7.1

التو افق الزواجي:

عرف بيرجس وكوتريل (Burgess \& Cottrell, 1939) التوافق الزواجي بأنه: تكامل الزوجين في رباط لا يتم فياه دمج شخصية كل منهما في الآخر

فحسب، وإنما يتفاعلان مع بعضهما ليكمل كل منهما الآخر، وذلك لتحقيق الرضا المتبادل والأهداف المشتركة.

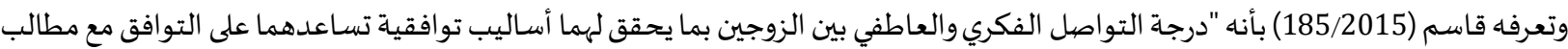

الزواج وتخطي ما يعترض حياتهما من عقبات وتحقيق قدر معقول من السعادة والرضا". ويعرف التوافق الزواجي في هذه الدراسة إجرائياً: هي الدرجة الكلية التي تحصل علئهيات عهديا المستجيبة من خلال الاجابة على فقرات مقياس التوافق الزواجي المستخدم في هذه الدراسة.

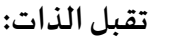

تعرفه رايف (Ryff,1989) بامتلاك الشخص موقفا إيجابياً تجاه الذات؛ يقر ويقبل جوانب متعددة من الذات، بما في ذلك الصفات الحسنة والسيئة ؛ يشعر بإيجابية تجاه الحياة الماضياة.

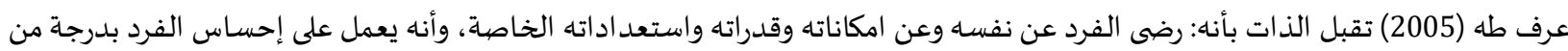
السعادة والراحة النفسية. وتعرف تقبل الذات في هذه الدراسـة إجرائياً: الدرجة التي تحصل علهها المستجيبة من خلال الاجابة على فقرات مقياس تقبل الذات المستخدم في

اتبعت الدراسة الحالية المنهج الوصفي الإرتباطي؛ وذلك لملاءمته لمتغيرات الدراسة الحالية.

2.2 - مجتمع الدراسة:

تكون مجتمع الدراسة من المعلمات المتزوجات اللاتي يعملن في مدارس محافظة شمال الشرقية والبالغ عددهن (3123) معلمة متزوجة. (وزارة

التربية والتعليم، 2021) 
تكونت عينة الدراسة من (618) معلمة متزوجة تعمل في مدارس محافظة شمال الشرقية، وقد تم اختيار العينة عن طريق توزيع الأدوات على المعلمات المتزوجات في جميع المدارس بطريقة عشوائية عن طريق برنامج جوجل درايف، وتم الرد من قبل 618 من تلكم المعلمات، وجدول (1) يبين توزيع

جدول(1): توزيع عينة الدراسة حسب عدد سنوات الزواج

\begin{tabular}{|c|c|c|}
\hline توزيع عينة الدراسة حسب عدد سنوات الزواج النسبة & 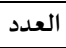 & عدد سنوات الزواج \\
\hline$\% 48$ & 294 & من 10 سنوات فأقل \\
\hline$\% 52$ & 324 & أكثر من 10 سنوات \\
\hline$\% 100$ & 618 & المجموع \\
\hline
\end{tabular}

4.2 - 2.2 أدوات الدراسة:

بغرض جمع البيانات تم استخدام مقياسين الأول مقياس التوافق الزواجي لقاسم (2015)، الذي تألف من أبعاد ثلاثة وقد بلغ معامل الثبات العام للمقياس (0.94)، أما المقياس الثاني فهو بعد تقبل الذات من مقياس السعادة النفسية لكارول رايف (Ryff, 1989)، حيث تتكون الصهورة الأصلية للمقياس الكلي من 84 فقرة موزعة على (6) أبعاد، وقد تم في الدراسة الحالية ترجمة بعد تقبل الذات المكات المكون من 14 فقرة إلى اللغة العربية.

5.2 الخصيائص السيكومترية لمقياس التو افق الزواجي في الدراسة الحالية: تم حساب الصددق الظاهري بعرض فقرات المقياس على 11 محكماً من تخصصيات مختلفة في الإرشاد النفسي والتربوي، والتربية الخاصة، التهائ، وعلم

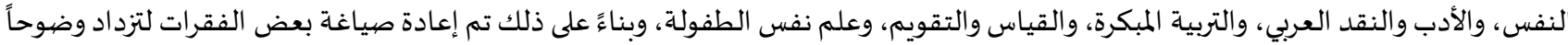

ولتلائم ما وضعت لقياساه، حيث تم تعديل الفقرات (20،26،29، كما تم حساب صداق الفقرات عن طريق حساب معامل الارتباط المصحح بين الفقرات والدرجة الكلية للبعد بعد حذف الفقرة حيث اتضح أن جميع الفقرات ترتبط بالبعد الذي تندرج تحته ارتباطاً جيداً، حيث كان معامل ارتباط الفقرات متقاربة وجميعها أكثر من 0.20 وبالتالي يمكن اعتبار فقرات المقياس صادقة وصالحة لما وضعت لقياسهاس. وتم حساب الاتساق الداخلي بين أبعاد المقياس والدرجة الكلية، وكذلك معاملات الثبات عن طريق معادلة ألفا لكرومباخ حيث يوضح الجدول 2

تلك المعاملات:

\begin{tabular}{|c|c|c|c|}
\hline ألفا لكرونباخ & معامل الارتباط بالبعد & عدد الفقرات & أبعاد المقياس \\
\hline 0.830 & $.745^{* *}$ & 8 & التواصل الفكري بين الزوجين \\
\hline 0.768 & $.745^{* *}$ & 12 & التواصل العاطفي بين الزوجين \\
\hline 0.783 & $.745^{* *}$ & 10 & حل الخلافات الزوجية \\
\hline 0.757 & & 30 & مقياس التو افق الزواجي ككل \\
\hline
\end{tabular}

يتضح من الجدول 2 أن هناك ارتباطاً قوياً بين كل بعد والدرجة الكلية للمقياس، وهذا يعد مؤشراً جيداً لصدق المقياس، كما أن معامل ألفا

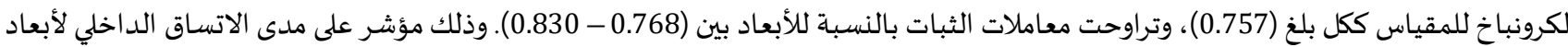

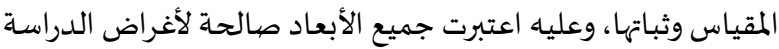

6.2. الخصيائص السيكومترية لمقياس تقبل الذات في الدراسـة الحالية: تم حساب الصددق الظاهري للمقياس بعرضها على 11 محكماً من تخصصيات مختلفة في الإرشاد النفسي والتربوي، والتربية الخاصية، وعلم النفس، والأدب والنقد العربي، والتربية المبكرة، والقياس والتقويم، وعلم نفس الطفولة، وبناءً على ذلك تم تعديل بعض العبارات وإعادة صياغتها لتزداد وضوحاً

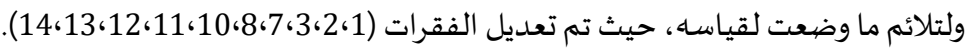
كما تم حساب صدق الفقرة وذلك عن طريق حساب معاملات الارتباط المعدل بين كل فقرة من فقرات المقياس مع الدرجة الكلية بعد حذف الفقرة، حيث اتضح أن جميع فقرات مقياس تقبل الذات لديها إرتباط مع المقياس ككل، حيث كان معامل الإرتباط أكبر من معامل ارتباطها المصحح 156. تم حذفها ليتبقى في المقياس 13 فقرة صادقة وصالحة لماوضعت لقياسها. 7.2 ثبات مقياس تقبل الذات: تم التحقق من ثبات مقياس تقبل الذات بحساب معامل ثبات المقياس ككل باستخدام معامل ألفا لكرونباخ (Cronbach’s Alpha)، واتضح أن معامل الثبات الكلي قد بلغ (774.). 
8.2 تصحيح المقياسين:

لتصحيح المقياسين تم تصنيف تصنيف المتوسطات الحسابية وفقاً للجدول (3) جدول (3): معيار التصحيح في المقياسين المعيار المعتمد في تفسيرنتائج السؤال الأول المتعلقة بتقبل الذات

\begin{tabular}{|c|c|c|c|c|c|}
\hline \multicolumn{3}{|c|}{ مقياس تقبل الذات } & \multicolumn{3}{|c|}{ مقياس التو افق الزواجي } \\
\hline المستوى & المتوسط & a & المستوى & المتوسط & م \\
\hline منخفض جداً & $2-1$ & 1 & ضعيف & $1.69-1.0$ & 1 \\
\hline منخفض & $3-2.1$ & 2 & متوسط & $2.49-1.7$ & 2 \\
\hline متوسط & $4-3.1$ & 3 & مرتفع & $3.0-2.5$ & 3 \\
\hline 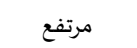 & $5-4.1$ & 4 & & & \\
\hline مرتفع جداً & $6-5.1$ & 5 & & & \\
\hline
\end{tabular}

9.2 إجراءات تطبيق الدراسـة:

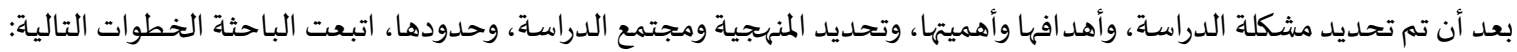
1. تم اختيار مقياس التوافق الزواجي لقاسم (2015)، وبعد تقبل الذات من مقياس رايف (Ryff, 1989) للسعادة النفسية وتمت ترجمته إلى اللغة

2. تم الحصول على الموافقات اللازمة لتطبيق أدوات الدراسـة. 3. تم إعد اد نسخة إلكترونية من المقاييس للتمكن من نشره بطريقة أسهل وأسرع مع التأكيد على عدم الإجابة إلا من قبل المعلمات المتزوجات المبات العاملات

$$
\text { في مد ارس محافظة شمال الشرقية. }
$$

4. تم استعادة عدد 618 من الاستجابات من المعلمات المتزوجات العاملات في مدارس محافظة شمال الشرقية. 5. تم جمع البيانات وتحليلها باستخدام الحزمة الإحصائية للعلوم الإنسانية والاجتماعية (SPSS)، والإجابة على الأسئلة ومناقشاتة النتائج. 6. تم الخروج بتوصيات ومقترحات مستقبلية.

10.2. الأسـاليب الإحصائية المستخدمة في هذه الدراسـة:

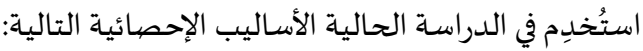

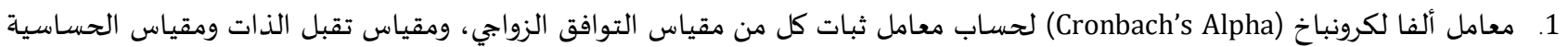
الانفعالية. 2. معامل ارتباط بيرسون (Pearson)، لحساب صددق المفردة، عن طريق حساب كل بعد مع الدرجة الكلية للبعد الذي تنتهي إليه في مقياس التوافق الزواجي، وحساب ارتباط الفقرات بالدرجة الكلية. 3. المتوسطات الحسابية والانحرافات المعيارية للإجابة على أسئلة الدراسة. باسة.

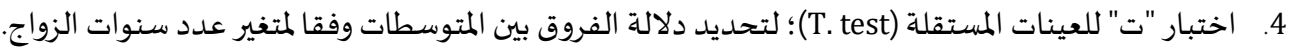
5. تحليل الانحدار.

3. نتائج الدراسة ومناقشتها وتفسيرها

يتناول هذا الجزء من الدراسة عرضا للنتائج الدراسة ومناقشتها وتفسيرها والتوصيات التي خرجت بها: 1.3. عرض النتائج المتعلقة بالسؤال الأول ومناقشته وتفسيره والذي نص على: ما مستوى التو افق الزواجي، وتقبل الذات، لدى المعلمات المتزوجات في محافظة شمال الشرقية؟ للإجابة على هذا السؤال تم استخراج المتوسطات الحسابية والانحرافات المعيارية لمستوى أداء أفراد العينة على مقياس التوافق الزواجي ومقياس تقبل الذات، ويوضح جدول(4) نتائج السؤال الأول. 
جدول (4): المتوسطات الحسابية والانحر افات المعيارية لمستوى آداء أفراد عينة الدراسة على مقياس التو افق الزواجي ومقياس تقبل الذات

\begin{tabular}{|c|c|c|c|c|}
\hline \multicolumn{2}{|c|}{ تــــــــل الــــات } & \multicolumn{3}{|c|}{ التـــو افق الزواجـي } \\
\hline الانحراف المعياري & المتوسط الحسابي & الانحراف المعياري & المتوسط الحسابي & البعد البع \\
\hline \multirow{3}{*}{.821} & \multirow{3}{*}{4.462} & .352 & 2.686 & التواصل الفكري \\
\hline & & .361 & 2.742 & التواصل العاطفي \\
\hline & & .330 & 2.589 & حل الخلافات \\
\hline .821 & 4.462 & .313 & 2.676 & المقياس ككل \\
\hline
\end{tabular}

مقياس التوافق الزواجي ثلاثي - مقياس تقبل الذات سـاسي. تظهر القيم الواردة في جدول(4) أن مستوى التوافق الزواجي للمقياس ككل لدى عينة الدراسة جاء إس مرتفعا بمتوسط حسابي بلغ (2.676) وانحراف

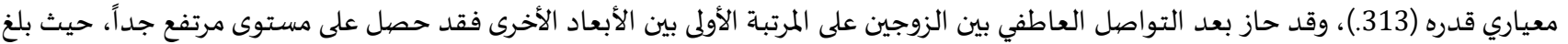

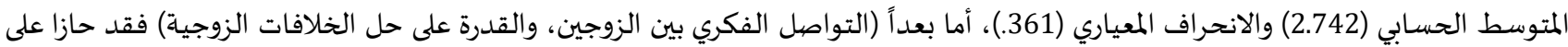
مستوى مرتفع، حيث بلغ المتوسط الحسابي في بعد التواصل الفكري بين الزوجين (2.686) بانحراف معياري قدره (352.)، أما مقدار المتوسط الحسابي

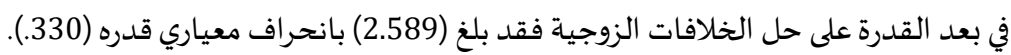
وقد يعزى ارتفاع مستوى التوافق الزواجي لدى عينة الدراسة إلى المستوى التعليمي الذي وصلت إليه المعلمة، مما قد يؤثر إيجاباً على التوافق

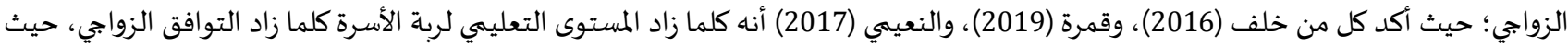
إن المستوى التعليمي يمكِّن الزوجة من تحمل ومواجهة الأعباء الخاصية بأمور الحياة الأسرية بشكل عام، والحياة الزوجية بشكل خاص، فهواصئ فهو يلعب دوراً

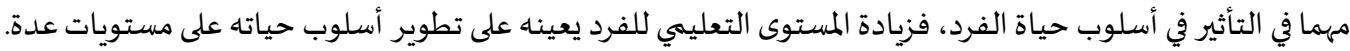

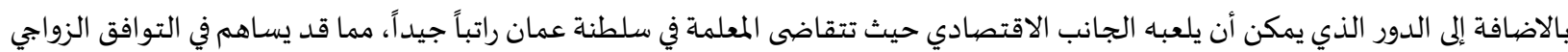
وهنا أشارت هلون (2017) أن الوضع الاقتصادي الجيد للأسرة يساعد على تلبية احتياجاتها، وبالتالي زيادة الاستقرار، و أضافت أحمد (2015) أن توفر

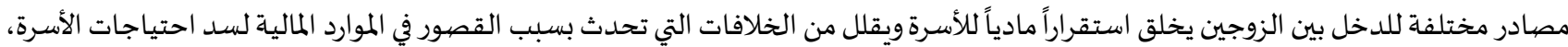

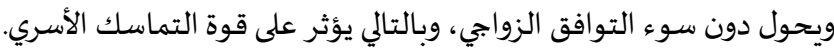

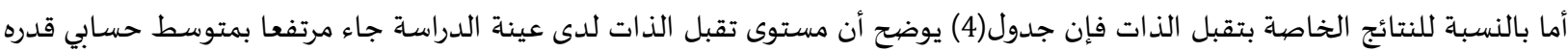

(4.462) وانحراف معياري (821.).

Zhu, Liu, Fu, ويمكن تفسير هذه النتيجة بمستوى الخبرة والوعي لدى عينة الدراسة في ضوء ما وضحاه كل من زهو وليو وفو وينج وزهانج وشي أن خبرة المعلم دائما ما تعزز لديه تقبل الذات، حيث أنه يكون في سعي مستمر لتطوير نفساه حتى يتمكن من القيام بعمله على أكمل وجهاء. إضافة إلى ما سبق فإن تعدد الأدوار التي تلعبها عينة الدراسة -فهي زوجة وموظفة ولديها علاقات مختلفة بالمجتمع من حولها- تعد في حد ذاتها معين لتقبل الذات، فهي لم تحكر نفسها في دور واحد ضيق الأفق، ولقد أكد كيرسون ولينجر (Carson \& Langer, 2006) أن من المعيقات التي تحول دون

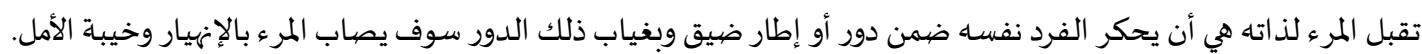
2.3. عرض النتائج المتعلقة بالسؤال الثاني وتفسيره والذي ينص على : هل توجد فروق ذات دلالة إحصائية في التو افق الزواجي لدى المعلمات

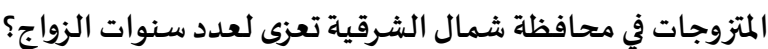
من أجل الإجابة على هذا السؤال تم استخدام المتوسطات الحسابية والانحرافات المعيارية واختبار (Independent T test) لمتغير عدد سنوات

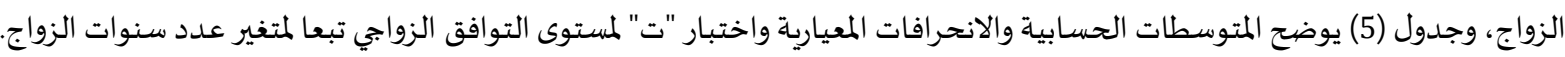
جدول (5): المتوسطات الحسابية والانحر افات المعيارية واختبار"ت" للتو افق الزواجي تبعا لعدد سنوات الزواج

\begin{tabular}{|c|c|c|c|c|c|c|}
\hline الدلالة & قيمة "ت" & الانحراف المعياري & المتوسط الحسابي & العدد & عدد سنوات الزواج & أبعاد المقياس \\
\hline \multirow[t]{2}{*}{0.82} & -0.22 & 0.33 & 2.69 & 294 & أقل من 10 سنوات & التواصل الفكري بين \\
\hline & & 0.35 & 2.69 & 324 & من 10 إلى 20 سنة & الزوجين \\
\hline \multirow[t]{3}{*}{0.38} & 0.86 & 0.34 & 2.76 & 294 & أقل من 10 سنوات & التواصل العاطفي \\
\hline & & 0.34 & 2.73 & 324 & من 10 إلى 20 سنة & بين الزوجين \\
\hline & & 0.32 & 2.60 & 294 & أقل من 10 سنوات & حل الخلافات \\
\hline 0.28 & 1.07 & 0.33 & 2.57 & 324 & من 10 إلى 20 سنة & الزوجية \\
\hline \multirow[t]{2}{*}{0.47} & 0.71 & 0.29 & 2.69 & 294 & أقل من 10 سنوات & المقياس \\
\hline & & 0.31 & 2.67 & 324 & من 10 إلى 20 سنة & ككل \\
\hline
\end{tabular}


ويتضح من جدول(5) عدم وجود فروق ذات دلالة إحصائية في التوافق الزواجي تعزى لعدد سنوات الزواج، حيث كانت قيمة "ت" غير دالة إحصائياً عند مستوى الدلالة (0.05)، وكذلك عدم وجود فروق ذات دلالة إحصائية في أبعاد التوافق الزواجي (التواصل الفكري، والتواصل العاطفي، وحل الخلافات الزوجية) فقد كانت قيمة "ت" غير دالة إحصائيا عند مستوى الدلالة (0.05). وهذا يعني أن مستوى التوافق الزواجي لا يتأثر بعدد سنوات الزواج.

يمكن أن تفسر هذه النتيجة بتشـابه البيئة الاجتماعية والثقافية التي تعيش فيها عينة الدراسة، فهي جميعها تنتهي إلى منطقة جغرافية واحدة

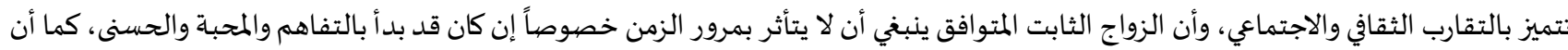

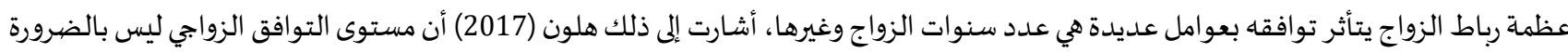

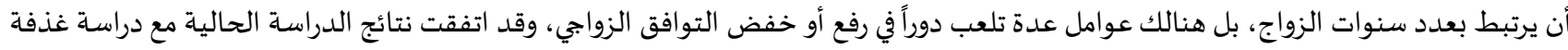

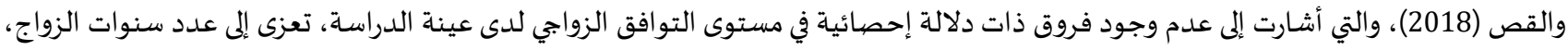

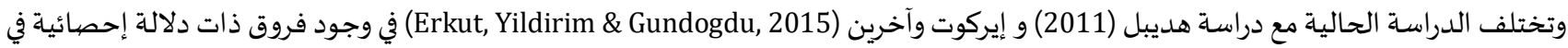

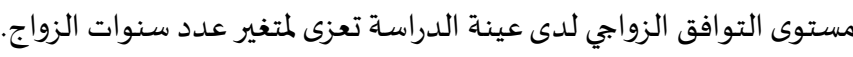
3.3. عرض النتائج المتعلقة بالسؤال الثالث ومناقشته وتفسيره والذي ينص على: ما مدى مساهمة تقبل الذات في التنبؤ بالتو افق الزواجي لدى

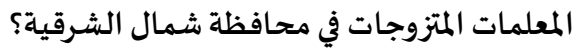
ولإجابة على هذا السؤال تم استخدام تحليل الانحدار الخطي البسيط. وتمهيداً لإجراء معادلة الانحدار تم حساب معامل الارتباط بين تقبل الذات

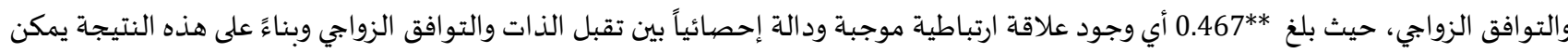
استخدام تحليل الانحدار الخطي البسيط، كما تم تحليل التباين للتأكد من صلاحية النموذج لعملية التنبؤ، والجدول (6) يبين ذلك.

\begin{tabular}{lccccc}
\multicolumn{5}{c}{ مصدر التباين } \\
\hline
\end{tabular}

توضح الأرقام والدلالات في الجدول (6) أن نموذج الانحدار ملائم لتفسير العلاقة والتنبؤ بها بين التوافق الزواجي وتقبل الذات، ويمكن للنموذج

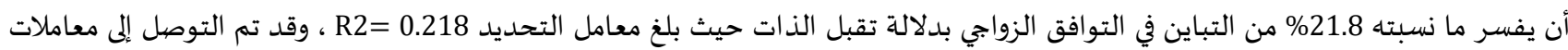
الانحدار البسيط للتنبؤ بمستوى التوافق الزواجي من خلال تقبل الذات لدى عينة الدراسـة، وجدول(7) يوضح ذلك.

\begin{tabular}{|c|c|c|c|c|}
\hline القيمة الاحتمالية & قيمة "ت" المحسسوبة & بيتا & معامل الانحدار & المتغير \\
\hline 0.000 & 23.73 & & 1.86 & قيمة الثابت \\
\hline 0.000 & 11.73 & 0.459 & 0.174 & تقبل الذات \\
\hline
\end{tabular}

توضح الأرقام والدلالات في الجدول (7) دلالة معاملات الارتباط مما يشير إلى هناك علاقة ارتباطية موجبة دالة إحصائياً بين التوافق الزواجي

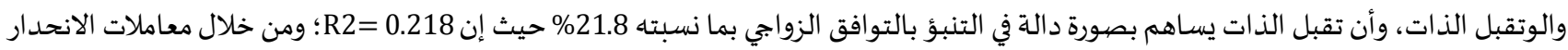
في الجدول (7) يمكن كتابة المعادلة الانحدارية التالية:

درجة التو افق الزواجي = 1.86 + (تقبل الذات × 0.174)

يتضح من هذه النتيجة أن تقبل الذات متنبئ جيد بالتوافق الزواجي حيث يفسر تقبل الذات نسبة 21.8\% من التباين في التوافق الزواجي؛ وذلك

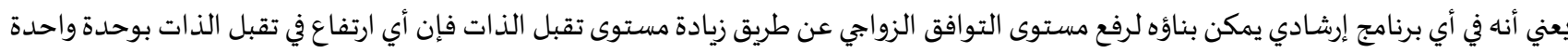

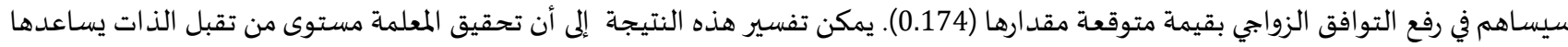

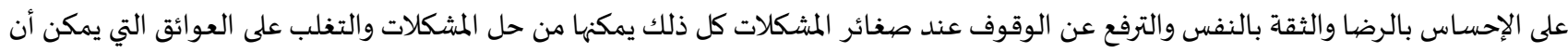

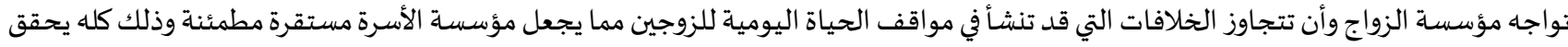

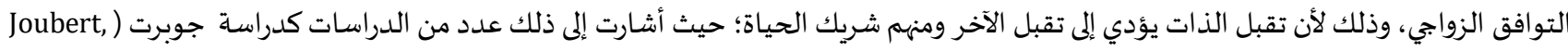

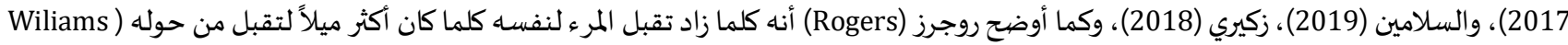


لع Lynn, 2010 ( وبالتالي إذا زاد تقبل المرء لمن حوله تصبح علاقته بهم وثيقة وسليمة؛ حيث إنه يدرك أههم قد يصيبون وقد يخطؤون لذلك لا داعي للشعور بالضيق والغضب والكره تجاههم؛ لأن هذه المشاعر بحد ذاتها تدمر العلاقهات فئات مهما كانت.

هالاستفادة من المستويات العالية للتوافق الزواجي في عمليات الإرشاد الأسري وحل المشكلات.

استفادة لجان التوفيق والمصالحة من العلاقة بين التوافق الزواجي وتقبل الذات في استخدام مدخل تقبل الذات لحل الخلافات بين الزوجين.

الاستفادة من العلاقة التبؤية لتقبل الذات بالتوافق الزواجي عند بناء برامج إرشادية لرفع مستوى التوافق الزواجي. استخدام عمليات رفع مستوى تقبل الذات عند الأزواج والزوجات في مجال الإرشاد الزواجي؛ وذلك لما لتقبل الذات من أثر واضح على التوافق مع

شريك الحياة.

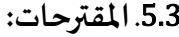

دراسة أثر متغيرات أخرى على التوافق الزواجي.

إعادة الدراسة الحالية على عينات مختلفة من المجتمع -غير المعلمات-، كأن تكون العينة العاملات في مجالات أخرى غير التعليم، أو أن تكون غير

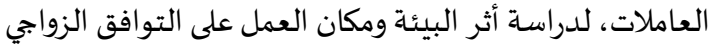

بناء وتجربة برنامج إرشاد جمعي لتنمية التوافق الزواجي، يمكن الاستفادة منها في الإرشاد الأسري.

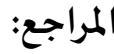

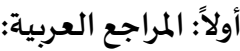

1. أحمد، سمية عباس إبراهيم (2015). أثر عمل المرأة على التوافق الزواجي: دراسة حالة العاملات العسكريات بمستشفى عائلات العسكري بأم درمان (رسالة ماجستير غير منشورة). جامعة النيلين، السودانه إسبران.

2. البريكي، حسن (2016). التوافق الزواجي وأثره على استقرار الأسرة. مجلة كلية الشريعة والدراسات الاسلامية: جامعة قطر 33 3ـ(2): 271- 312.

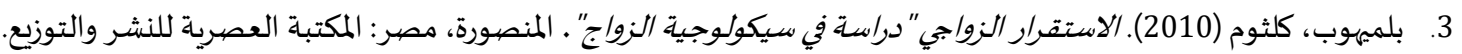

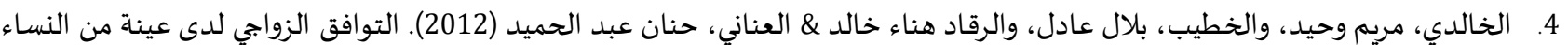

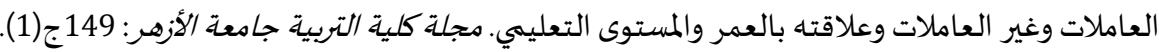

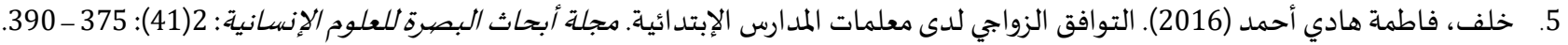

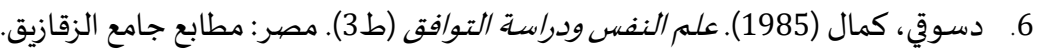
7. زكيري، هاجر (2018). التوافق الزواجي وعلاقته بالتوافق النفسي لدى الأستاذة الجامعية المتزوجة. رسالة ماجستير غير منشورة، جامعة محمد خضير بسكرة، الجزائر

8. زهران، محمد حامد عبد السلام (2011). فاعلية برنامج ارشادي في تحسين التوافق الزواجي وتقدير الذات وخفض حدة القلق والاكتئاب، المجلة المصرية للدراسات النفسية: مصر. (21)73: 497-548. 9. سليمان، سناء محمد (2005). التوافق الزواجي واستقرار الاسرة من منظور: اسلامي.. نفسي.. اجتماعي. القاهرة، مصري: عالم الكتب للنشر والتوزيع

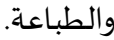

10. السلامين، إيمان (2019). التوافق الزواجي وعلاقته بالصحة النفسية لدى النساء العبيات في شمال فلسطين. رسالة ماجستير غير منشورة جامعة الخليل فلسطين

11. الشاذلي، عبد الحميد (2004). الواجبات المدرسية والتوافق النفسي. الاسكندرية، مصر: الدار الجامعية للطباعة والنشر والتوزيع. 12. صحاف، خلود بنت محمد علي (1436). التوافق الزواجي وعلاقته بالاستقرار الأسري لدى عينة من المتزوجين بمدينة مكاة المكرمة، رسالة ماجستير غير منشورة، جامعة أم القرى، المملكة العربية السعودية. 13. طه، فرج عبد القادر (2009). موسوعة علم النفس والتحليل النفسي. القاهرة، مصرئ مكتبة الانجلو المصرية. 14. غذفة، شريفة والفص، صليحة (2018). الذكاء الوجداني وعلاقته بالتوافق الزواجي "دراسة تحليلية من منظور الصحة النفسية". مجلة وحدة

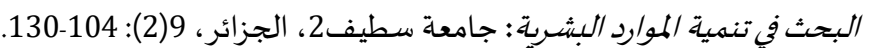
15. قاسم، أماني محمد رفعت(2015). الأفكار الإيجابية لخبرات الزوجين وعلاقتها بالتوافق الزواجي. مجلة الخدمة الاجتماعية: لجمعية المصرية للأخصائيين الاجتماعيين (53): 175-219. 
16. قمرة، هنادي محمد عمر سراج (2019). التوافق الزواجي وعلاقته بمعايير اختيار شريك الحياة. مجلة القراءة والمعرفة: (215): 311 - 336. 17. الكندري، أحمد محمد مبارك (1992). علم النفس الأسري (ط.2). الكويت: مكتبة الفلاح للنشر والتوزيع.

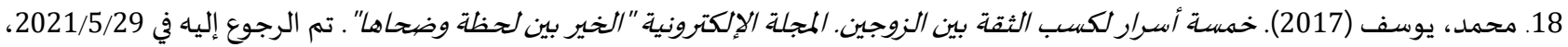
الساعة 6:12م، من خلال: https://2u.pw/2U88g

19. مناني، نبيل؛ نوغي، فاطمة (2013). عوامل سوء التوافق الزواجي. مجلة علوم الإنسان والمجتمع: جامعة بسكر، الجزائر (6): 235 - 255.

20. النعيمي، هدى بنت خليفة بن أحمد (2017).وعي المتزوجين بمقومات التوافق الزواجي في المجتمع (رسالة ماجستير غير منشورة). جامعة السلطان

قابوس، سلطنة عمان.

21. النمر ، آمال زكريا (2016). تقبل الذات وعلاقته بكل من تقبل الآخر للدى طلبة الجامعة. (رسالة ماجستير غير منشورة). جامعة القاهرة، مصر.

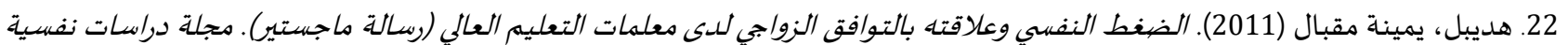

$$
\text { وتربوية: الجزائر. 7: 226- } 240 .
$$

23. هلون، ملاك الفرد نعيم (2017). التوافق الزواجي وعلاقته بالمستوى الاقتصادي والاجتماعي في ضيوء بعض المتغيرات لدى العاملات في منطقة حيفا

(دراسة ماجستير غير منشورة). جامعة عمان العبربية، الأردن.

ثانياً: المراجع الأجنبية:

1. APA Concies Dictionary of Psychology (2009). American Osychology Association, Washington, DC, P454.

2. Bali, A., Dhingra, R., \& Baru, A. (2010). Marital adjustment of childless couples. Journal of Social Sciences, 24(1): 73-76. https://doi.org/10.1080/09718923.2010.11892839

3. Burgess, E \& Cottrell, L (1939). Predicting Success or Failure in Marriage. Social Forces Journal, 18(4): 591-592.

4. Carson, S. H., \& Langer, E. J. (2006). Mindfulness and self-acceptance. Journal of rational-emotive and cognitive-behavior therapy, 24(1): 29-43.

5. Corsini, R. (2002). The Dictionary of Psychology. New York: Brunner-Routledge.

6. Erol, R. Y., \& Orth, U. (2017). Self-esteem and the quality of romantic relationships. European Psychologist.21 (4): $274-283$. https://doi.org/10.1027/1016-9040/a000259

7. Gonzalez, D. M. (2002). Client Variables and psychotherapy outcomes. In D.J. Cain \& J. Seeman (Eds), Humanistic Psychotherapies: Handbook of research and practice (p. 559-578). Washington, DC: American Psychological Association. Guildford press.

8. Khorasani, N. H., Hosseini, M., Matbouei, M., Khafri, S., Vasli, P., \& Vardanjani, A. E. (2017). The study of relationship between self-efficacy and marital satisfaction of couples referring to the community health centers of Babol in 2015. Journal of Advances in Medicine and Medical Research, 19(9): 1-9. https://doi.org/10.9734/bjmmr/2017/29999

9. Mutlu, B., Erkut, Z., Yıldırım, Z., \& Gündoğdu, N. (2018). A review on the relationship between marital adjustment and maternal attachment. Revista da Associação Médica Brasileira, 64(3): 243-252. https://doi.org/10.1590/1806-9282.64.03.243

10. Nema,S. (2013). Effect Of Marital Adjustment in Middle - Aged Adults. International Journal of Scientific and Research Publications, 3(6): 250 - 315.

11. Ryff, C. D. (1989). Happiness is everything, or is it? Explorations on the meaning of psychological well-being. Journal of personality and social psychology, $57(6)$.

12. Taghizadeh, M. E., \& Kalhori, E. (2015). Relation between self-esteem with marital satisfaction of employed women in payam-e-Noor university. Mediterranean Journal of Social Sciences, 6(6 S6), 41-41.

13. Yadalijamaloye, Z., Naseri, E., Shoshtari, M., Khaledian, M., \& Ahrami, R. (2013). Relationships between self-esteem and marital satisfaction among women. Psychology and Behavioral Sciences, 2(3): 124-129. https://doi.org/10.11648/j.pbs.20130203.17 
المجلة الدولية للدراسـات التربوية والنفسية

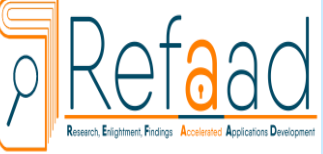

www.refaad.com
International Journal of Educational \& Psychological Studies (EPS)

Journal Homepage: https://www.refaad.com/views/EPSR/Home.aspx

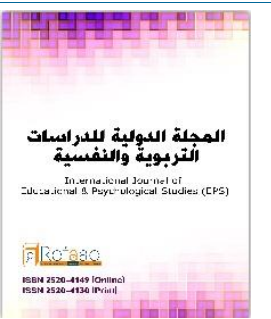

\title{
The relationship of marital adjustment with self-acceptance among the female teachers of al Sharqiya north governorate
}

\author{
Hafsa Hamoud Nasser Al-Mahrezi \\ Master's in Psychological Counseling, University of Nizwa, Sultanate of Oman
}

\section{Khalifa Ahmed Al-Qasabi}

Assistant Professor of Educational Psychology, University of Nizwa, Sultanate of Oman kah73@unizwa.edu.om

Received : 1/6/2021 Revised : 14/6/2021 Accepted : 22/6/2021 DOI : https://doi.org/10.31559/EPS2021.10.2.10

Abstract: The study seeks to explore the relationship between marital harmony and self-acceptance for the female teachers in North Ash-Sharqiyah Governorate. The sample of the study consisted of (618) married female teachers. To achieving the objectives of the study, the following tools were applied; Firstly, the Marital Harmony Scale (Qasim, 2015), and secondly, the Self-Acceptance Dimension from the Psychological Happiness Scale of Carol Ryff. The results of the study indicated that the level marital harmony and self-acceptance were high. Moreover, the results indicated that the number of years of marriage did not influence the marital harmony, as there were no statistically significant differences in each of them. In addition, the calculation of the correlations among the variables showed that there is a positive statistically significant relationship between marital harmony and self-acceptance, By application of regression analysis, it can be said that marital harmony can be anticipated through self-acceptance, as well as the level of marital harmony can be elevated through guidance programs that apply the elevation of the level of self-acceptance, The study recommends taking advantage of the correlational and predictive relationship between self-acceptance and marital compatibility to resolve marital disputes, and build counseling programs in the field of family counseling.

Keywords: marital harmony; self-acceptance; marital harmony and self-acceptance; anticipation of marital harmony.

\section{References:}

1. Ahmd, Smyh 'bas Ebrahym (2015). Athr 'ml Almrah 'la Altwafq Alzwajy: Drash Halh Al'amlat Al'skryat Bmstshfa 'a'lat Al'skry Bam Drman (Rsalt Majstyr Ghyr Mnshwrh). Jam't Alnylyn, Alswdan.

2. Albryky, Hsn (2016). Altwafq Alzwajy Wathrh 'la Astqrar Alasrh. Mjlt Klyt Alshry'h Waldrasat Alaslamyh: Jam't Qtr 33(2): 271- 312 .

3. Blmyhwb, Klthwm (2010). Alastqrar Alzwajy "Drash Fy Sykwlwjyh Alzwaj". Almnswrh, Msr: Almktbh Al'sryh Llnshr Waltwzy'.

4. Dswqy, Kmal (1985). 'Im Alnfs Wdrash Altwafq (T3). Msr: Mtab' Jam' Alzqazyq.

5. Ghdfh, Shryfh Walfs, Slyhh (2018). Aldka' Alwjdany W'laqth Baltwafq Alzwajy "Drash Thlylyh Mn Mnzwr Alshh Alnfsyh". Mjlt Whdt Albhth Fy Tnmyt Almward Albshryh: Jam't Styf2, Aljza'r, 9(2): 104-130.

6. Hdybl, Ymynh Mqbal (2011). Aldght Alnfsy W'laqth Baltwafq Alzwajy Lda M'lmat Alt'lym Al'aly (Rsalt Majstyr). Mjlt Drasat Nfsyh Wtrbwyh: Aljza'r. 7: 226- 240.

7. Hlwn, Mlak Alfrd N'ym (2017). Altwafq Alzwajy W'laqth Balmstwa Alaqtsady Walajtma'y Fy Dw' B'd Almtghyrat Lda Al'amlat Fy Mntqt Hyfa (Drast Majstyr Ghyr Mnshwrh). Jam't 'man Al'rbyh, Alardn.

8. Alkhaldy, Mrym Whyd, Walkhtyb, Blal 'adl, Walrqad Hna' Khald \& Al'nany, Hnan 'bd Alhmyd (2012). Altwafq Alzwajy Lda 'ynh Mn Alnsa' Al'amlat Wghyr Al'amlat W'laqth Bal'mr Walmstwa Alt'lymy. Mjlt Klyt Altrbyh Jam't Alazhr: 149j (1).

9. Khlf, Fatmh Hady Ahmd (2016). Altwafq Alzwajy Lda M'lmat Almdars Alebtda'yh. Mjlt Abhath Albsrh Ll'lwm Alensanyh: 2(41): $375-390$. 
10. Alkndry, Ahmd Mhmd Mbark (1992). 'Im Alnfs Alasry (T.2). Alkwyt: Mktbt Alflah Llnshr Waltwzy'.

11. Mhmd, Ywsf (2017). Khmsh Asrar Lksb Althqh Byn Alzwjyn. Almjlh Alelktrwnyh "Alkhyr Byn Lhzh Wdhaha". Tm Alrjw' Elyh Fy 29/5/2021, Alsa'eh 6:12m, Mn Khlal: https://2u.pw/2u88g.

12. Mnany, Nbyl: Nwghy, Fatmh (2013). 'waml Sw' Altwafq Alzwajy. Mjlt 'lwm Alensan Walmjtm': Jam't Bskr, Aljza'r (6): 235 -255 .

13. Aln'ymy, Hda Bnt Khlyfh Bn Ahmd (2017). W'y Almtzwjyn Bmqwmat Altwafq Alzwajy Fy Almjtm' (Rsalt Majstyr Ghyr Mnshwrh). Jam't Alsltan Qabws, Sltnt 'man.

14. Alnmr, Amal Zkrya (2016). Tqbl Aldat W'laqth Bkl Mn Tqbl Alakhr Lda Tlbt Aljam'h. (Rsalt Majstyr Ghyr Mnshwrh). Jam't Alqahrh, Msr.

15. Qasm, Amany Mhmd Rf'et(2015). Alafkar Aleyjabyh Lkhbrat Alzwjyn W'laqtha Baltwafq Alzwajy. Mjlh Alkhdmh Alajtma'yh: Ljm'y Almsryh Llakhsa'yyn Alajtma'yyn (53): 175-219.

16. Qmrh, Hnady Mhmd 'mr Sraj (2019). Altwafq Alzwajy W'laqth Bm'ayyr Akhtyar Shryk Alhyah. Mjlt Alqra'h Walm'rfh: (215): $311-336$.

17. Alshadly, 'bd Alhmyd (2004). Alwajbat Almdrsyh Waltwafq Alnfsy. Alaskndryh, Msr: Aldar Aljam'yh Lltba'h Walnshr Waltwzy'.

18. Shaf, Khlwd Bnt Mhmd 'ly (1436). Altwafq Alzwajy W'laqth Balastqrar Alasry Lda 'ynh Mn Almtzwjyn Bmdynt Mkh Almkrmh, Rsalt Majstyr Ghyr Mnshwrh, Jam't Am Alqra, Almmlkh Al'rbyh Als'wdyh.

19. Slyman, Sna' Mhmd (2005). Altwafq Alzwajy Wastqrar Alasrh Mn Mnzwr: Aslamy.. Nfsy.. Ajtma'y. Alqahrh, Msr: 'alm Alktb Llnshr Waltwzy' Waltba'h.

20. Alslamyn, Eyman (2019). Altwafq Alzwajy W'laqth Balshh Alnfsyh Lda Alnsa' Al'rbyat Fy Shmal Flstyn. Rsalt Majstyr Ghyr Mnshwrh Jam't Alkhlyl Flstyn.

21. Th, Frj 'bd Alqadr (2009). Mwsw't 'Im Alnfs Walthlyl Alnfsy. Alqahrh, Msr: Mktbt Alanjlw Almsryh.

22. Zhran, Mhmd Hamd 'Ebd Alslam (2011). Fa'lyt Brnamj Arshady Fy Thsyn Altwafq Alzwajy Wtqdyr Aldat Wkhfd Hdh Alqlq Walakt'ab, Almjlh Almsryh Lldrasat Alnfsyh: Msr. (21)73: 497-548.

23. Zkyry, Hajr (2018). Altwafq Alzwajy W'laqth Baltwafq Alnfsy Lda Alastadh Aljam'yh Almtzwjh. Rsalt Majstyr Ghyr Mnshwrh, Jam't Mhmd Khdyr Bskrh, Aljza'r 
الملحقق (1): مقياس تقبل الذات في صيورته النهائية

\begin{tabular}{|c|c|c|c|c|c|c|c|}
\hline أو افق بشـدة & أو افق جززئيا & أو افق قليلا & أعارض قليلا & أعارض جزئيا & أعارض بشدة & 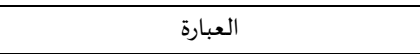 & $ت$ \\
\hline & & & & & & أشعر بالرضا عندما أتذكر قصة حياتي & 1 \\
\hline & & & & & & أشعر بالثقة تجاه نفسي & 2 \\
\hline & & & & & & أشعر أن هناك أشخاصا كثيرين استفادوا من & 3 \\
\hline & & & & & & هناك العديد من الأشياء التي سأغيرها في نفسي & 4 \\
\hline & & & & & & تعجبني معظم جوانب شخصيتي & 5 \\
\hline & & & & & & أشعر بالإحباط عندما أفكر فيما حققته في & 6 \\
\hline & & & & & & أفتخر بنفسي & 7 \\
\hline & & & & & & أرى أن حياة كثيٍٍ من الناس أفضل من حياتي & 8 \\
\hline & & & & & & نظرتي لنفسي إيجابية كنظرة بعض الناس & 9 \\
\hline & & & & & & أستيقظ وأنا أشعر بالإحباط اتجاه الطريقة التي & 10 \\
\hline & & & & & & لو أتيحت لي الفرصة لغيرت الماضي الخاص بي & 11 \\
\hline & & & & & & 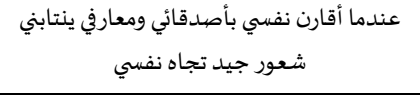 & 12 \\
\hline & & & & & & أشعر أن لدي نقاط ضعف اكثر من الآخرين & 13 \\
\hline
\end{tabular}

الملحقق(2): مقياس التوافق الزواجي في صبورته النهائية

\begin{tabular}{|c|c|c|c|c|}
\hline$y$ & إلى حد ما & 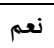 & 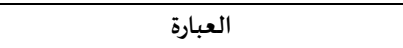 & $ت$ \\
\hline \multicolumn{5}{|c|}{ 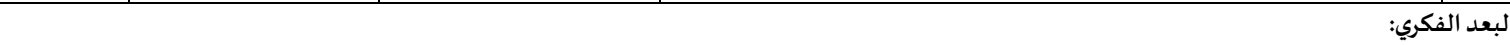 } \\
\hline & & & ندبر شؤوننا الاقتصادية & 1 \\
\hline & & & نتشارك في اتخاذ القرارات للتعامل فيما بيننا & 2 \\
\hline & & & نتشارك في الأعباء المنزلية & 3 \\
\hline & & & أصارح زوجي بمشاعري & 4 \\
\hline & & & نشجع بعضينا على الادخار & 5 \\
\hline & & & نتحاور لإدارة شؤون الأسرة & 6 \\
\hline & & & نتشارك معا في مصروفات الأسرة & 7 \\
\hline & & & نتفق على أهداف مشتركة لحياتنا & 8 \\
\hline \multicolumn{5}{|c|}{ البعد العاطفي: } \\
\hline & & & يسعد كلانا الآخر & 9 \\
\hline & & & نحرص على قضاء أوقات الفراغ معا & 10 \\
\hline & & & نستمع إلى رأي بعضنا & 11 \\
\hline & & & نهتم بتجديد طرق تواصلنا معا & 12 \\
\hline & & & أهتم بمظهري حرصا على الرضا المشترك & 13 \\
\hline & & & نشعر بالراحة النفسية أثناء تواجدنا معا & 14 \\
\hline & & & نستمتع بحياتنا الخاصة & 15 \\
\hline & & & لن يرضى أيّ منا بأي شريك آخر & 16 \\
\hline & & & تواصلنا المشترك يحقق لنا الرضا الزواجي & 17 \\
\hline & & & نعيش بيئة نفسية إيجابية داخل منزلنا & 18 \\
\hline & & & يشعر بعضنا البعض بالأمان & 19 \\
\hline & & & يساند كل واحد منا الآخر & 20 \\
\hline \multicolumn{5}{|c|}{ بعد حل الخلافات الزوجية: } \\
\hline
\end{tabular}




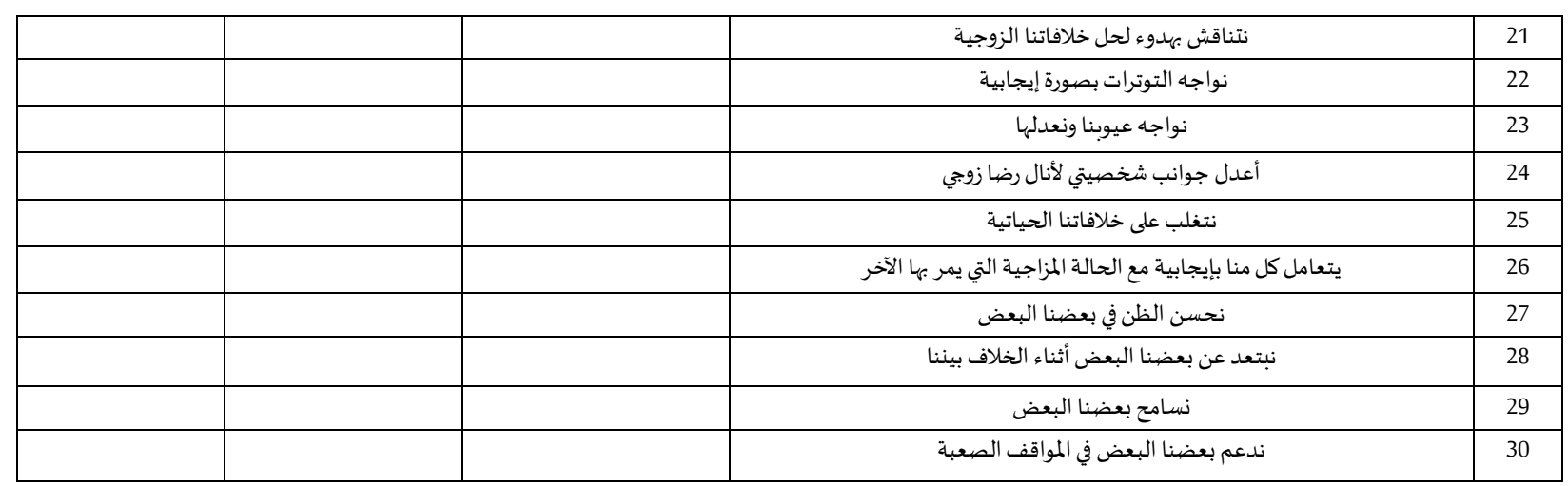

